\title{
LA OBJECIÓN DE CONCIENCIA DE LOS JUECES DEL REGISTRO CIVIL PARA CELEBRAR MATRIMONIOS ENTRE PERSONAS DEL MISMO SEXO
}

ULISES ERIC HERnÁNDEZ MARTínEZ ${ }^{1}$

RESUMEN: La objeción conciencia analizada desde el punto de vista del derecho constitucional, entendida como el incumplimiento de un individuo de determinada disposición legal que le obliga a actuar en contra de su conciencia o le impide obrar conforme a ella, no puede ser ejercida por los servidores públicos encargados de celebrar los matrimonios, quienes por mandato legal llevar a cabo este tipo de uniones entre personas del mismo sexo, lo que podría ocasionar una intromisión injustificada del estado en su fuero interno.

Palabras clave: Objeción de conciencia, derechos humanos, servidores públicos, matrimonio, personas del mismo sexo.

ABSTRACT:

KeYwords: Conscientious objection, human rights, public servers, marriage, persons of the same sex.

SUMARIO: I. Nota introductoria; II. Concepto de objeción de conciencia; III. El derecho a la libertad de conciencia en México; IV. Obligaciones de los jueces del Registro Civil; V. Perspectiva en derecho comparado; VI. A manera de conclusiones; VII. Fuentes de consulta.

\section{Nota introductoria}

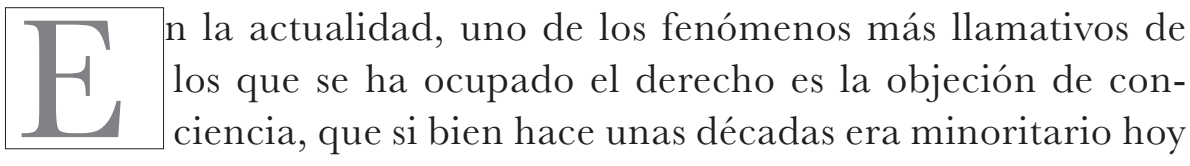

1 Secretario de Estudio y Cuenta del Segundo Tribunal en Materia Administrativa del Tercer Circuito, con residencia en Zapopan, Jalisco. <hernandez_martinez0789@hotmail.com>. 
ha experimentado un fenómeno de expansión que hace que sea más aconsejable hablar de objeciones de conciencia en plural, ${ }^{2}$ toda vez que progresivamente se han planteado nuevas modalidades de objeción de conciencia, entre ellas las relacionadas con la celebración del matrimonio entre personas del mismo sexo.

Dichos matrimonios constituyen a su vez, una de las cuestiones jurídicas que más debate ha generado en los últimos años, aspecto que viene ligado a una progresiva aceptación de las prácticas homosexuales, así como a una disociación entre unión matrimonial y procreación, ${ }^{3}$ es decir, el concepto de matrimonio se ha ido alejando de la concepción metafísica, instrumentalista y tradicionalista tan arraigada en el modelo religioso, teniendo como consecuencia una visión voluntarista e individualista debido a la secularización de esta institución. ${ }^{4}$

Así, en México un primer paso para asegurar el reconocimiento jurídico de este tipo de uniones tuvo lugar en 2006 con leyes estatales que reconocían parejas de hecho sin diferenciar entre heterosexuales y homosexuales, ${ }^{5}$ posteriormente en 2009, la ciudad de México reformó el Código Civil para dar reconocimiento jurídico al matrimonio para parejas del mismo sexo, situación que dio lugar a que el 27 de enero de 2010, el Procurador General de República promoviera acción de inconstitucionalidad ante la Suprema Corte de Justicia de la Nación, en la que solicitó la invalidez de la reforma

2 Rafael Navarro-Valls, "Las objeciones de conciencia", en Ferrer Ortiz, Javier (coord.), Derecho Eclesiástico del Estado Español, Pamplona, Eunsa, 2004, p. 145.

3 Daniel Borillo, "Pluralisme conjugal ou hiérarchie des sexualités? La reconnaissance juridique des couples homosexuels dans l'Union Européenne", en McGill Law Fournal, Montreal, núm. 46, 2001, p. 877

4 Fernando Arlettaz, Matrimonio homosexual y secularización, México, UNAM, 2015, pp. 49-51.

5 Ibidem p. 68. 
a los artículos 146 y 391 del Código Civil del Distrito Federal, ${ }^{6}$ la cual fue registrada con el número 2/2010.

La Suprema Corte de Justicia de la Nación, al resolver la acción de inconstitucionalidad mencionada determinó que estos matrimonios eran acordes al texto constitucional así mismo, resolvió que debían reconocerse como válidos en toda la federación.

Finalmente, el diecinueve de junio de dos mil quince, se publicó en el Semanario Judicial de la Federación la jurisprudencia 43/2015 de la Primera Sala, en la que se concretizó que es inconstitucional la ley de cualquier entidad federativa que, por un lado, considere que la finalidad del matrimonio es la procreación y/o que lo defina como el que se celebra entre un hombre y una mujer. ${ }^{7}$

De esta forma, todos los tribunales federales ante los que se presentaron juicios de amparo derivado de la negativa de los jueces del registro civil a celebrar matrimonios por ser entre personas del mismo sexo en los estados que aún conservan en sus Códigos Civiles el requisito de que el matrimonio sea entre un hombre y una mujer, tuvieron la obligación de resolver conforme a la jurisprudencia antes mencionada y en consecuencia, obligar a dichos jueces a celebrar los matrimonios que les fueron solicitados, abriendo así la posibilidad de que en México las personas del mismo sexo puedan contraer matrimonio.

Los mencionados antecedentes sólo tienen por objeto patentizar que la celebración de matrimonios entre personas del mismo sexo ya es una realidad jurídica y jurisprudencialmente reconocida en México, sin que el presente trabajo tenga como finalidad emitir un juicio de valor respecto de si los matrimonios entre personas del

6 "El matrimonio entre personas del mismo sexo en la legislación del Distrito Federal y sus efectos jurídicos" en Decisiones relevantes de la Suprema Corte de Fusticia de la Nación, núm. 65, México, Suprema Corte de Justicia de la Nación, UNAM, Instituto de Investigaciones Jurídicas, 2013, p. 45.

7 1a./J. 43/2015 (10a.), Gaceta del Semanario Judicial de la Federación, Décima Época, Libro 19, Junio de 2015, Tomo I, Pag. 536. 
mismo sexo deben gozar de reconocimiento legal, ni poner en tela de juicio los razonamientos empleados por la Suprema Corte de Justicia de la Nación para adoptar el criterio imperante, toda vez que ello sería materia de un análisis especializado en ese tema, el cual es ajeno al presente trabajo.

Así, derivado de las reformas al Código Civil de la Ciudad de México que reconoce que las personas del mismo sexo pueden contraer matrimonio entre sí, se genera el problema de si los jueces del registro civil de esa entidad pueden objetar en conciencia para abstenerse de llevar a cabo uniones matrimoniales con estas características, pues por su condición de servidores públicos encargados de la celebración de los matrimonios tienen el deber de llevar a cabo este tipo de uniones que pueden diferir de su concepción tradicional o religiosa del matrimonio, lo que podría atentar contra su conciencia.

Así mismo, si los jueces del registro civil de las entidades federativas en las que no se encuentra reconocido en sus respectivos códigos civiles el matrimonio entre personas del mismo sexo, a los que mediante sentencias amparo se les ordena celebrar estos matrimonios, pueden objetar en conciencia para cumplimentar personalmente esa sentencia.

Precisado lo anterior, el objetivo de este trabajo es analizar desde un punto de vista objetivo la posibilidad de que los Jueces del Registro Civil puedan objetar en conciencia para abstenerse de celebrar este tipo de uniones, para ello primeramente habrá de estudiar lo que debe entenderse por objeción de conciencia, así como sus elementos, posteriormente sí en México con base en el derecho a la libertad de conciencia existe el reconocimiento legal de esta figura, posteriormente se verá cuáles son las obligaciones de los jueces del registro civil así como su grado de participación en los matrimonios entre personas del mismo sexo y si actualmente gozan de la posibilidad de plantear una objeción de conciencia, acto seguido se analizará lo acontecido en diversos países sobre este tópico, para fi- 
nalmente llegar a una conclusión que sin pretender lograr una modificación legislativa o justificar el estado actual de las cosas plantee posibles proyecciones a futuro teniendo en cuenta sus potenciales consecuencias, tanto favorables como adversas.

\section{Concepto de objeción de conciencia}

En principio considero necesario mencionar que la objeción de conciencia deriva de una nueva y más profunda comprensión del sistema jurídico, el cual es propio de las democracias modernas fundadas sobre valores más que sobre normas, lo que ha transformado al Estado de ser un "Estado de Derecho" a un "Estado de Derechos". ${ }^{8}$ La importancia de esta figura estriba en la colisión entre la norma legal que impone un deber de hacer y la norma ética o moral que se opone a ese deber.

No existe un concepto homogéneo respecto de la objeción de conciencia, pues ésta puede analizarse desde la perspectiva de la ciencia jurídica, como desde el punto de vista de la filosofía moral o política.

Así algunos autores conciben la objeción de conciencia como un concepto jurídico, al ser un medio de desobediencia de quienes manifiestan una oposición abierta a obedecer el mandato legal por considerarlo una intromisión injustificada y abusiva del estado en su fuero interior. ${ }^{9}$

Entre las diversas definiciones de objeción de conciencia, conviene citar, entre otras, la del Profesor Ramos Morente, que señala que la objeción de conciencia "en su sentido más amplio puede entenderse como la rebeldía del individuo ante lo que considera

8 Rafael Navarro-Valls, "La objeción de conciencia a los matrimonios entre personas del mismo sexo", en Persona y Derecho, Pamplona, número 53, 2005, pp. 259-260.

9 Dora María Sierra Madero, La objeción de conciencia en México. Bases para un adecuado marco jurídico, México, UNAM, 2012, p. 14. 
una intromisión del Estado en un ámbito que no le pertenece: su conciencia. O bien como la oposición a una ley, norma o imposición que contraste con los valores, creencias o convicciones de una persona". ${ }^{10}$

Siguiendo esa línea, está la definición del profesor Oliver, quien señala: "De forma muy genérica, podríamos definir la objeción de conciencia como la negativa a cumplir un mandato de la autoridad o una norma jurídica, invocando la existencia en el fuero de la conciencia de un imperativo que prohíbe dicho cumplimiento". ${ }^{11}$

Así mismo, aproximándonos a un concepto más jurídico, conviene citar la definición del maestro Martínez-Torron, quien señala que la objeción de conciencia es la negativa del individuo, por razones de conciencia, a sujetarse a una conducta jurídica exigible, ya provenga dicha obligación de una norma o de un contrato. ${ }^{12}$

En el ámbito nacional, la objeción de conciencia es un tema relativamente novedoso en la literatura jurídica, sin embargo existen algunos trabajos que pueden servir de guía para aproximarnos a un concepto de lo que se debe entender por objeción de conciencia, como la definición que hace Trejo Osorno, señalado que es: "una postura individual contraria a la ley, actos de autoridad e incluso autoridades laborales. Esta postura de discrepancia normalmente es generada por creencias religiosas, ideológicas, principios éticos o morales y tiene como finalidad la no aplicación de la ley o acto en cuestión o su sanción". ${ }^{13}$

Para efectos de este trabajo, considero que la definición más apropiada es la que nos proporciona la doctora Sierra Madero

10 Idem.

11 Ibidem p. 15.

12 Javier Martínez-Torron, "Las objeciones de conciencia y los intereses generales del ordenamiento", en Revista de la Facultad de Derecho de la Universidad Complutense, Madrid, No. 79, 1992, p. 200.

13 Luis Alberto Trejo Osorno, La objeción de conciencia en México, México, Porrúa, 2010, p. 29. 
quien define la objeción de conciencia desde un punto de vista no sólo jurídico, sino desde la perspectiva del derecho constitucional al señalar que es "una concreción de la libertad de conciencia que dentro de los justos límites, lleva a un individuo a incumplir una determinada disposición legal que le obliga -bajo sanción o privación de un beneficio- a obrar en contra de su conciencia o le impide obrar conforme a ella", ${ }^{14}$ así mismo hace la aclaración que es posible dar un concepto general de objeción de conciencia siempre y cuando quede claro que existen diversos supuestos de objeción de conciencia y que cada uno merece un tratamiento particular. ${ }^{15}$

Partiendo de la definición antes mencionada, esta autora señala cinco elementos esenciales de la objeción de conciencia, ${ }^{16}$ a saber:

a) Ampara un comportamiento individual del objetor que no persigue la derogación general de la norma, simplemente solicita que se le exceptúe del cumplimiento de la norma por motivos de conciencia.

b) Debe existir un claro deber legal que prescriba una determinada conducta o que la prohíba para el objetor, que se oponga a sus convicciones morales.

c) Los motivos por los cuales se pretende la excepción deben ser de conciencia, es decir, que el objetor considere que la realización de la conducta legalmente exigible contradice su código ético, porque siente el imperativo de obedecer a sus convicciones de conciencia, aun por encima del deber legal.

Sobre este aspecto, es importante señalar que el Tribunal Europeo de Derechos Humanos ha matizado que no toda ideología es susceptible de invocarse en la objeción de conciencia, sino que sola-

\footnotetext{
14 Dora María Sierra Madero, op. cit, p. 17.

15 Idem.

${ }^{16}$ Ibidem pp. 17-21.
} 
mente aquellas que sean "convicciones" o "creencias", sin importar si se apoyan en consideraciones religiosas, es decir, deben provenir de un sistema de pensamiento coherente y suficientemente orgánico y sincero. ${ }^{17}$

d) La consecuencia jurídica del incumplimiento o inobservancia del deber jurídico debe ser una sanción o, de ser el caso, la privación de un beneficio al que sólo puede acceder si se realiza la conducta que le impone la autoridad.

e) El último elemento que señala la autora es el respeto a ciertos límites, es decir, que de permitirse la objeción no se afecten derechos de terceros, ni se lesione el orden público o el bien común.

Es importante precisar que, al igual que en otros supuestos, tratándose de la objeción de conciencia la no aplicación de la norma debe tener un carácter excepcional; ello es así ya que cuando se convierte en un fenómeno recurrente es susceptible de lesionar al Estado de Derecho, en tanto que la conducta de quienes no acatan la norma y de los agentes de la autoridad que no la aplican, no debe presentarse como una regularidad tendencia. ${ }^{18}$

Sobre este carácter excepcional el Tribunal Constitucional Español en la STC 161/1987, de 27 de octubre señalado:

[...] la objeción de conciencia con carácter general, es decir, el derecho a ser eximido del cumplimiento de los deberes constitucionales o legales, por resultar ese cumplimiento contrario a las propias convicciones, no está reconocido ni cabe imaginar que lo estuviera en nuestro derecho en derecho alguno, pues significaría la negación

17 Rafael Navarro Valls, "La objeción de conciencia a los matrimonios...", op. cit. p. 277.

18 Diego Valadez, "La no aplicación de las normas y el Estado de Derecho", en Boletín Mexicano de Derecho Comparado, México, nueva serie, año XXXV, núm. 103, enero-abril de 2002, pp. 281-286. 
misma de la idea de Estado. Lo que puede ocurrir es que sea admitida excepcionalmente respecto a un deber concreto. ${ }^{19}$

Enmarcada la objeción de conciencia dentro de estas coordenadas, se distingue claramente de la llamada desobediencia civil, que consiste en la negativa de un individuo de acatar la norma con la finalidad de desencadenar los mecanismos represivos del estado y así conseguir su modificación. ${ }^{20}$

La doctrina ${ }^{21}$ ha distinguido entre objeción de conciencia secundum legem o contra legem. La primera se identifica con aquellos supuestos en que la propia legislación prevé una posible salida para ellos casos de conflicto entre la conciencia y el deber impuesto por una norma. En México el supuesto más claro y el único es el de la objeción de conciencia del personal sanitario, como en la Ciudad México en favor de los médicos a quienes corresponda practicar la interrupción legal del embarazo y cuyas creencias religiosas o convicciones personales sean contrarias a tal procedimiento, teniendo la obligación de referir a la mujer con un médico no objetor. En cambio la objeción contra legem es la pura y real objeción en la que la ley no prevé una posible alternativa para aquellos obligados a los que su cumplimiento les acaree un conflicto de conciencia. Lo que ocurre en el caso de la objeción de conciencia a intervenir en la celebración de matrimonios entre personas del mismo sexo, donde las leyes que lo regulan no contemplan una cláusula de conciencia. Consecuentemente la objeción de conciencia en estos casos aparece revista de mayores dificultades en cuando a reconocimiento y posibilidades de actuación.

19 Cfr., <http://hj.tribunalconstitucional.es/es/Resolucion/Show/892>, consultada el 15 de abril de 2018.

20 Santiago Cañamares Arribas, "Las objeciones de conciencia", en Miguel Ángel Jusdado Ruiz-Capillas (dir.), Derecho Eclesiástico del Estado, Madrid, Colex, 2012, p. 113.

21 Rafael Navarro-Valls, "Las objeciones de conciencia”, op. cit. p. 146. 


\section{iII. El derecho a la libertad de conciencia en México}

En México la objeción de conciencia no se encuentra expresamente regulada en la Constitución, sin embargo, los artículos 24 y 130 de la Carta Magna, reconocen la libertad de conciencia y de culto.

Por su parte, en el artículo 1o de la Ley de Asociaciones Religiosas y Culto Público, la objeción de conciencia se encuentra expresamente prohibida, de la manera siguiente:

Artículo 1o. La presente ley, fundada en el principio histórico de la separación del Estado y las iglesias, así como en la libertad de creencias religiosas, iglesias y culto público. Sus normas son de orden público y de observancia general en el territorio nacional.

Las convicciones religiosas no eximen en ningún caso del cumplimiento de las leyes del país. Nadie podrá alegar motivos religiosos para evadir las responsabilidades y obligaciones prescritas en las leyes. ${ }^{22}$

Se entiende que la razón de ser de la prohibición a la objeción de conciencia, consiste en evitar que el orden jurídico quede sometido a normas de carácter religioso, pues de aceptarse en toda su amplitud el derecho a la objeción de conciencia en todos los casos que el particular lo considere, como se dijo anteriormente, se llegaría al extremo de atentar en contra de la idea misma del estado.

Sin embargo, tampoco puede adoptarse una posición sumamente formalista que llegue al grado de afirmar que conforme al artículo antes referido quedada vedada de forma absoluta la objeción de conciencia en México, ya que existen diversos instrumentos internacionales suscritos por nuestro país, en los que se consagra el derecho a la objeción de conciencia.

22 Cfr., <http://bovmsilap.scjn.pjf.gob.mx/Buscador/Paginas/wfArticulado Fast.aspx?q=BHGCbWrG7ukiUiW/WEuu/p8LleK/aAiRW/NIyDBMGeD26 fQH4D1AS76ba9QpHZqdlVXcNDeh0Y9LdZ0j9Mrorw==>, consultada el 12 de abril de 2018>. 
La Declaración Universal de Derechos Humanos en su artículo 18 consagra que toda persona tiene derecho a la libertad de pensamiento, de conciencia y de religión; este derecho incluye la libertad de cambiar de religión o de creencia, así como la libertad de manifestar su religión o su creencia, individual y colectivamente, tanto en público como en privado, por la enseñanza, la práctica, el culto y la observancia, así mismo en su artículo 29 dispone que toda persona tiene deberes respecto de la comunidad, puesto que sólo en ella puede desarrollar libre y plena su personalidad y que en el ejercicio de sus derechos y en el disfrute de sus libertades, toda persona estará solamente sujeta a las limitaciones establecidas por la ley con el único fin de asegurar el reconocimiento y respeto de los derechos y libertades de los demás, y de satisfacer las justas exigencias de la moral, del orden público y del bienestar general en una sociedad democrática. ${ }^{23}$

De lo anterior se desprende que este artículo establece una afirmación en favor de la objeción de conciencia, ya que establece que las limitaciones prescritas en la ley sólo deben asegurar el reconocimiento y respeto a los demás "y nunca podrá pensarse por el hecho de que una conducta o prohibición se encuentra vista en la norma, ésta deba cumplirse, pues podría ser totalitaria, dogmática y antidemocrática". ${ }^{24}$

El Pacto Internacional de Derechos Civiles y Políticos en su artículo 18 establece que toda persona tiene derecho a la libertad de pensamiento, de conciencia y de religión; este derecho incluye la libertad de tener o de adoptar la religión o las creencias de su elección, así como la libertad de manifestar su religión o sus creencias, individual o colectivamente tanto en público como en privado, mediante el culto, celebración de ritos, las prácticas y la enseñanza,

23 Cffr., <http://www.un.org/es/universal-declaration-human-rights/>, consultada el 17 de abril de 2018.

24 Martha Elena Soto Obregón, Objeción de conciencia: ¿Testigos de Jehová vs. símbolos patrios?, México, Plaza y Valdés, 2003, p. 82. 
que nadie será objeto de medidas coercitivas que puedan menoscabar su libertad de tener o adoptar la religión o las creencias de su elección, que la libertad de manifestar la propia religión o las propias creencias estará sujeta únicamente a las limitaciones prescritas por la ley que sean necesarias para proteger la seguridad, el orden, la salud o la moral públicos, o los derechos y libertades fundamentales de los demás. ${ }^{25}$

La Convención Americana Sobre Derechos Humanos en su artículo 12 establece que toda persona tiene derecho a la libertad de conciencia y de religión, que ese derecho implica la libertad de conservar su religión o creencias, o de cambiar de religión o de creencias, así como la libertad de profesar y divulgar su religión o sus creencias, individual o colectivamente, tanto en público como en privado, que nadie puede ser objeto de medidas restrictivas que puedan menoscabar la libertad de conservar su religión o sus creencias o de cambiar de religión o de creencias. Señala además que la libertad de manifestar la propia religión y las propias creencias está sujeta únicamente a las limitaciones prescritas por la ley y que sean necesarias para proteger la seguridad, el orden o la moral públicos o los derechos o libertades de los demás. ${ }^{26}$

En los dos instrumentos internaciones citados el último término se contempla de forma clara la libertad de conciencia y, por consiguiente, el derecho a la objeción de conciencia que deben gozar los ciudadanos de los Estados que hayan adoptado los mismos. ${ }^{27}$

En ese contexto y con motivo de las reformas a diversos artículos de la Constitución publicadas en el Diario Oficial de la Federación

25 Cfr., <http://bovmsilap.scjn.pjf.gob.mx/Buscador/Paginas/wfArticulado Fast.aspx?q=zmlkJ/89AXJJKRY4OR4AdHR5D7ybEDVwR9piyudTPqf7Otv f1sBBSN7TV9QyUgNtOf/RTQxb1HYEV5YnPs3rZg==>, consultada el 18 de abril de 2018.

26 Cfr., <https://www.oas.org/dil/esp/tratados_b-32_convencion_american a_sobre_derechos_humanos.htm>, consultada el 18 de abril de 2018 .

27 Luis Alberto Trejo Osorno, op. cit. pp. 72-75. 
los días 6 y 10 de junio de 2011, conocidas coloquialmente como la reforma de derechos humanos de 2011, México adoptó la doctrina del bloque de constitucionalidad, por la que se ubica a los tratados internacionales en materia de derechos humanos en el mismo nivel jerárquico de la Ley Fundamental, y así se aumentan nuevos derechos fundamentales no incluidos en la Carta Magna.

Lo antes mencionado permite concluir que el derecho a la objeción de conciencia se encuentra incorporado a la Constitución, con motivo de la adopción, en nuestro país del bloque de constitucionalidad, al ubicarse los tratados internacionales en materia de derechos humanos antes mencionados en el mismo plano jerárquico que las demás disposiciones de la Ley Fundamental, ${ }^{28}$ sin embargo considero que esta inclusión de la objeción de conciencia no debe considerarse ilimitada, pues como ser vio le debe revestir un carácter excepcional respecto de deberes concretos para no atentar contra la idea misma del Estado.

Cabe mencionar que existen algunos supuestos en que la objeción de conciencia sí se encuentra regulada, esto es en dos entidades federativas: la ciudad de México y el Estado de Jalisco.

En la ciudad de México, el artículo 59 de la Ley de Salud de dicha entidad, establece el derecho del objetar en conciencia al médico a quien corresponda practicar la interrupción legal del embarazo y cuyas creencias religiosas o convicciones personales sean contrarias a tal procedimiento, teniendo la obligación de referir a la mujer con un médico no objetor, sin embargo, contiene la salvaguarda de que cuando sea urgente la interrupción legal del embarazo para salvaguardar la salud o la vida de la mujer, no podrá invocarse la objeción de conciencia; así mismo establece una obligación a cargo de las instituciones públicas de salud consistente garantizar la oportuna prestación de los servicios y la permanente disponibilidad

28 Jaime Allier Campuzano, "Improcedencia de la objeción de conciencia planteada por un juzgador", en Revista del Instituto de la Fudicatura Federal, México, num. 33, 2012, pp. 15-18. 
de personal de salud no objetor de conciencia en la materia, ${ }^{29} \sin$ embargo cabe señalar que conforme a este disposición el ejercicio de este derecho se restringió sólo a los médicos excluyendo al resto del personal de salud que participan en dicho procedimiento. ${ }^{30}$

Por su parte, en Jalisco, el artículo 18 ter de la Ley de Salud de dicho estado, ${ }^{31}$ de manera más amplia, otorga a todos los servidores públicos que forman parte del sistema estatal de salud, el derecho a hacer valer la objeción de conciencia y excusarse de participar en todos aquellos programas, actividades, prácticas, tratamientos, métodos o investigaciones que contravengan su libertad de conciencia con base en sus valores, principios éticos o creencias religiosas, con la misma salvedad antes mencionada en el sentido de que no podrá hacer valer ese derecho cuando la negativa del objetor de conciencia implique poner en riesgo la salud o vida del paciente, sin que éste pueda ser derivado a otros integrantes del sistema de salud que lo atiendan debidamente, debiendo en consecuencia aplicar las medidas médicas necesarias. Y va más allá señalando aspectos procedimentales ya que obliga a la Secretaría de Salud a emitir las disposiciones y lineamientos para manifestar la objeción de conciencia, sin que puedan limitar el ejercicio de ese derecho o generar discriminación en el empleo hacia quien lo haga valer.

Siguiendo esta tendencia, recientemente a nivel federal el veintidós de marzo de este año, la cámara de senadores aprobó la minuta del decreto con el que se aprobó la iniciativa remitida por la cámara de Diputados en la que se contempla agregar el artículo 10 bis a la Ley General de Salud, ${ }^{32}$ en el que se propone que el personal médi-

29 Cfr., <http://www.aldf.gob.mx/archivo-c034f9df29cc68890266a$50380 f 5 c 8$ ab.pdf>, consultada el 18 de abril de 2018.

30 Dora María Sierra Madero, op. cit, p. 200.

31 Cfr., <http://congresoweb.congresojal.gob.mx/BibliotecaVirtual/busqued asleyes/Listado.cfm\#Leyes>, consultada el 18 de abril de 2018.

32 Cfr., <http://www.senado.gob.mx/index.php?ver=sp\&mn=2\&sm=1\&id= $2231>$, consultada del 24 de abril de 2018. 
co y de enfermería que forme parte del Sistema Nacional de Salud, podrá ejercer la objeción de conciencia y excusarse de participar en la prestación de servicios que establece la ley. Sin embargo, también contiene la limitación de que cuando se ponga en riesgo la vida del paciente o se trata de una urgencia médica, no podrá invocarse la objeción de conciencia, en caso contrario se incurrirá en la causal de responsabilidad profesional.

iv. Obligaciones de los jueces del registro civil de la Ciudad de México

Según lo dispone el artículo 35 del Código Civil del Distrito Federal, está a cargo de las y los Jueces del Registro Civil autorizar los actos del estado civil de las y los mexicanos y extranjeros en el Distrito Federal, al realizarse el hecho o el acto de que se trate, y extender las actas relativas a los matrimonios entre otras.

Para comprender mejor las obligaciones de los Jueces del Registro Civil en lo concerniente a la celebración de los matrimonios, así como para evidenciar que su intervención en el procedimiento no es meramente declarativa o de fedatario, es importante establecer cuáles son los pasos a seguir para quienes deseen contraer nupcias, así conforme al artículo 97 de la aludida legislación las personas que pretendan contraer matrimonio deberán presentar un escrito ante el Juez del Registro Civil de su elección, con los requisitos que ahí se establecen, aquí cabe señalar la importancia de este artículo al disponer que será ante al juez del Registro Civil de su elección, lo que implica que los futuros contrayentes tienen el derecho elegir ante qué juez acudir siempre y cuando cumplan con los demás requisitos legalmente exigidos.

Aun vez presentando el escrito, el Juez del Registro Civil hará del conocimiento de los pretendientes que es un requisito previo a la celebración del matrimonio, el tramitar y obtener un certificado expedido por el propio registro en el que se haga constar si alguno 
de ellos se encuentra inscrito en el Registro de Deudores Alimentarios Morosos, así como tomar el curso prenupcial impartido por el Gobierno del Distrito Federal a través de la Dirección General del Registro Civil.

A la solicitud de matrimonio los pretendientes deben adjuntar, entre otros documentos, un convenio que celebren con relación a sus bienes presentes y a los que adquieran durante el matrimonio, y en caso de que por falta de conocimientos no puedan redactar el convenio mencionado el Juez del Registro Civil tendrá la obligación de redactarlo con los datos que los mismos pretendientes le suministren. ${ }^{33}$

Una vez cumplido lo anterior el juez del Registro Civil a quien se presentó la solicitud de matrimonio con todos los requisitos, hará que los pretendientes reconozcan ante él y por separado sus firmas y sostengan su voluntad para contraerlo, ponderando la veracidad de que alguno de los contrayentes no haya sido sentenciado por violencia familiar. ${ }^{34}$

Acto seguido se celebrará el matrimonio dentro de los ocho días siguientes a la presentación de la solicitud, en el lugar, día y hora que se señale para tal efecto, ${ }^{35}$ en donde deberán estar presentes, ante el Juez del Registro Civil, los pretendientes o su apoderado especial, acto continuo, el Juez del Registro Civil leerá en voz alta el acta respectiva y les hará saber los derechos y obligaciones legales que contraen con el matrimonio, para posteriormente preguntar a cada uno de los pretendientes si es su voluntad unirse en matrimonio, y si están conformes, los declarará unidos en nombre de la ley y de la sociedad, así mismo en caso de que los contrayentes así lo deseen podrán leerse los votos matrimoniales que hayan elaborado, con la asesoría y apoyo del personal del Registro Civil. ${ }^{36}$

\footnotetext{
33 Artículo 99 del Código Civil para el Distrito Federal.

34 Artículo 100 del Código Civil para el Distrito Federal.

35 Artículo 101 del Código Civil para el Distrito Federal.

36 Artículo 102 del Código Civil para el Distrito Federal.
} 
Cabe mencionar que el acta de matrimonio será firmada por el Juez del Registro Civil, los contrayentes y las demás personas que hubieren intervenido si supieren y pudieren hacerlo. ${ }^{37}$

También el Juez del Registro Civil que tenga conocimiento de que los pretendientes tienen impedimento para contraer matrimonio, levantará un acta, ante dos testigos, en la que hará constar los datos que le hagan suponer que existe el impedimento. ${ }^{38}$

De lo anterior se advierte que la actuación de los Jueces del Registro Civil no se circunscribe solamente a la verificación de documentos y a dar fe de la celebración del matrimonio, sino que su función va más allá, e implica actuar activamente con los contrayentes durante todo el proceso legal previsto para poder contraer nupcias.

En efecto, el Juez del Registro Civil, conviene enfatizar que es elegido por las partes, participa activamente con los contrayentes pues deberá hacerles de su conocimiento la obligación de obtener el certificado en el que se haga constar si alguno de ellos se encuentra inscrito en el Registro de Deudores Alimentarios Morosos, así como de tomar el curso prenupcial; en caso de necesitarlo los contrayentes, deberá redactar el convenio que celebren con relación a sus bienes presentes y a los que adquieran durante el matrimonio; deberá hacerlos comparecer ante él y por separado para que reconozcan sus firmas y sostengan su voluntad para contraer matrimonio; deberá leer en voz alta el acta respectiva y les hará saber los derechos y obligaciones legales que contraen con el matrimonio, para posteriormente preguntar a cada uno de los pretendientes si es su voluntad unirse en matrimonio, y si están conformes, los declarará unidos en nombre de la ley y de la sociedad; deberá firmar el acta de matrimonio; y, en caso de que los contrayentes lo deseen deberá asesorarlos y apoyarlos para elaborar los votos matrimoniales.

\footnotetext{
37 Artículo 103 del Código Civil para el Distrito Federal.

38 Artículo 105 del Código Civil para el Distrito Federal.
} 
Así mismo interviene en la verificación de que no existan impedimentos para celebrar matrimonios, pues en caso de tener noticia de la existencia de alguno deberá levantar el acta correspondiente.

Nótese que en todos los anteriores supuestos se ha utilizado de forma intencional el vocablo "deberá", para enfatizar que las anteriores intervenciones del Juez del Registro Civil no son potestativas para él, sino que suponen una obligación legal de cumplir con cada uno de los deberes ahí mencionados.

Así mismo, existe disposición legal que impone una sanción a los jueces que no lleven a cabo las anteriores obligaciones, en efecto, la propia legislación establece que los Jueces del Registro Civil sólo podrán negarse a autorizar un matrimonio, cuando por los términos de la solicitud, por el conocimiento de los interesados o por denuncia en forma, tuvieren noticia de que alguno de los pretendientes, o los dos carecen de aptitud legal para celebrar el matrimonio. ${ }^{39}$

En concordancia con lo anterior se dispone que el Juez del Registro Civil, que sin motivo justificado, retarde la celebración de un matrimonio, sea sancionado la primera vez con multa de $\$ 1,000.00$ y en caso de reincidencia con destitución del cargo. ${ }^{40}$

Todo lo anterior sirve para evidenciar que conforme al código civil, el Juez del Registro Civil elegido por los contrayentes debe de celebrar los matrimonios que, una vez cumplidos los requisitos legales, le sean solicitados, sin poderse negar a participar en los mismos alegando razones de conciencia, es decir, la objeción de conciencia para los oficiales del registro civil en la Ciudad de México se encuentra legalmente prescrita.

$\mathrm{Al}$ respecto cabe mencionar que con motivo de las reformas al Código Civil del Distrito Federal que permitió los matrimonios entre personas del mismo sexo, el diputado Fidel Suárez Vivanco, del Partido Revolucionario Institucional presentó una iniciativa que

\footnotetext{
39 Artículo 111 del Código Civil para el Distrito Federal.

40 Artículo 112 del Código Civil para el Distrito Federal.
} 
preveía la posibilidad de reconocer la objeción de conciencia en el supuesto en estudio, misma que hasta la fecha no ha sido aprobada, pero que "refleja en cierta forma el sentir de un amplio sector de la población". 41

Respecto de los Jueces u Oficiales del Registro Civil, según sea su denominación conforme a cada ley estatal, en las Entidades Federativas en las que legalmente se sigue considerando en esencia al matrimonio como "la unión entre un hombre y una mujer" la situación no es muy distinta.

Derivado de la jurisprudencia 43/2015 de la Primera Sala de la Suprema Corte de Justicia de la Nación, que considera que es inconstitucional la ley de cualquier entidad federativa que, por un lado, considere que la finalidad del matrimonio es la procreación y/o que lo defina como el que se celebra entre un hombre y una mujer, se han presentado gran cantidad de juicios de amparo en contra de esas disposiciones, los cuales a partir de la publicación de la mencionada jurisprudencia han sido concedidos para el efecto de que se desincorpore de la esfera jurídica de los quejosos la parte relativa del artículo correspondiente y en consecuencia, los Jueces u Oficiales del Registro Civil, quienes fungen como autoridad responsable, procedan a aceptar la solicitud de matrimonio de los peticionarios del amparo y obren en consecuencia, realizando todas las gestiones necesarias que estén dentro de sus atribuciones, para que los promoventes puedan unirse en matrimonio, con las formalidades que la ley establece. ${ }^{42}$

De ahí que, al haber sido señalado el Juez o Oficial del Registro Civil como autoridad responsable éste se encuentra legalmente

41 Dora María Sierra Madero, op. cit, p. 203.

$42 \mathrm{Al}$ respecto ver amparo indirecto 176/2018-I, del índice del Juez Primero de Distrito en el Estado de Guanajuato; amparo en revisión 84/2017 del Tercer Tribunal Colegiado en Materias Administrativa y Civil del Vigésimo Segundo Circuito; amparo en revisión 174/2016 del Tercer Tribunal Colegiado en Materias Civil y de Trabajo del Quinto Circuito, entre otros. 
constreñido a su cumplimiento sin poder hacer valer cuestiones de conciencia para eximirse del cumplimiento de la sentencia de amparo, toda vez que, la Ley de Amparo no contempla tal cuestión en el capítulo respectivo del cumplimiento de las sentencias, anulando a que, de no cumplir con la sentencia el servidor público respectivo se hace acreedor a las penas ahí establecidas. ${ }^{43}$

\section{v. Perspectiva en derecho comparado}

En México a la fecha, quien esto escribe no encontró que se haya presentado algún caso ante la Suprema Corte de Justicia de la Nación, o ante los Tribunales de la Federación en el que un Juez del Registro Civil se niegue a celebrar matrimonios entre personas del mismo sexo por razones de conciencia, en el mundo son diversos los casos que han acontecido, sosteniendo a veces los tribunales posiciones contradictoras, estado algunos a favor, otros en contra y en algunas otras legislaciones reconociendo legalmente la objeción de conciencia a la celebración de matrimonios entre personas del mismo sexo.

Respecto de este tema, la Corte Europea de Derechos Humanos en el caso Eweida and others vs The United Kingdom, analizó el caso de Lillian Ladele, una cristiana que sostenía la visión de que el matrimonio es la unión entre un hombre y una mujer y que los matrimonios entre personas del mismo sexo son contrarios a la ley divina, Ladele trabajaba para el London Borough of Islington desde 1992, es decir antes de que entrara en vigor de la Civil Partnership Act 2004, que permite el matrimonio entre personas del mismo sexo.

En un principio las autoridades locales permitieron arreglos informales entre los servidores públicos para que, quienes tuvieran una objeción de conciencia sincera no celebraran este tipo de uniones y

43 Ver artículos 192 a 198 de la Ley de Amparo. 
fuerana sustituidos, sin embargo posteriormente hubo protestas de colegas homosexuales que se sintieron victimizados y después de los procedimientos disciplinarios respectivos fue separada de su cargo.

El Tribunal Europeo de Derechos Humanos estimó que no hubo violación a los derechos humanos de la peticionaria, sin embargo no se pronunció frontalmente respecto del problema planteado, pues determinó que:

The court generally allows the national authorities a wide margin of appreciation when it comes to striking a balance between competing convention rights[...]. In all the circumstances, the Court does not consider that the national authorities, that is the local authority employer which brought the disciplinary proceedings and also the domestic courts which rejected the applicant's discrimination claim, exceeded the margin of appreciation available to them. It cannot, therefore, be said that there has been a violation of article 14 taken in conjunction with article 9 in respect of the third applicant. ${ }^{44}$

En un caso similar, pero con un final diametralmente opuesto, también en el Reino Unido, Margaret Jones, empleada del Central Bedforshire Council, fue separada de su cargo por negarse a celebrar matrimonios entre personas del mismo sexo, sin embargo después de un procedimiento de apelación interno ante el propio consejo, éste determinó que no había tomado una visión balanceada de sus creencias, y que el consejo no había analizado todas las opciones posibles de manera suficiente, por lo que se le ofreció de vuelta su trabajo. ${ }^{45}$

Cabe mencionar que en este caso, la situación no llego hasta los tribunales judiciales, sino que fue resuelta dentro de la propia administración, lo que pone de manifiesto que alcanzar acuerdos

44 Cfr., <http://hudoc.echr.coe.int/webservices/content/pdf/001-115881?T ID=pxlmztpkug $>$, consultada el 10 de abril de 2018 .

45 Cfr., <https://www.secularism.org.uk/news/2014/09/secularists-express-c oncern-over-council-decision-to-accommodate-religious-refusal-to-conduct-same -sex-weddings $1>$, consultada el 25 de abril de 2018. 
para respetar las objeciones de conciencia, sin la necesidad de acudir a los tribunales será siempre un resultado más pacífico y menos traumático. ${ }^{46}$

En España, el Tribunal Supremo resolvió el recurso contencioso-administrativo 69/2007, planteado por un juez de Registro Civil que por sus creencias religiosas solicitó ser eximido de su función de celebrar matrimonios entre personas del mismo sexo, al respecto sostuvo que la jurisprudencia española no ofrecía base para afirmar la existencia a un derecho a la objeción de conciencia de carácter general.

De igual forma, para desestimar la pretensión del solicitante determinó que:

En efecto, al juez encargado del Registro Civil no se le exige el cumplimiento de deberes ajenos a su función registral ni, mucho menos, participar en actos de trascendencia religiosa. La labor que debe realizar es de carácter técnico- jurídico y está prescrita en la Ley. Por tanto, ni desde el punto de vista fáctico, ni desde el doctrinal cabe hablar de precedente aplicable a este supuesto. ${ }^{47}$

Siguiendo esa misma línea, el Consejo Constitucional Francés en la decisión no. 2013-353 QPG de 18 de octubre de 2013, al resolver un asunto propuesto por varios alcaldes que se negaban a llevar a cabo matrimonios entre personas del mismo sexo por razones de conciencia, determinó que debe asegurarse el funcionamiento y la neutralidad del estado civil, por lo que no podían negarse a llevar a cabo sus funciones por razones de conciencia, al respecto sostuvo:

46 Rafael Palomino, "Objeción de conciencia de los notarios españoles con motivo de la nueva ley de jurisdicción voluntaria”, en Revista Jurídica Digital UANDES, España, 2017, pp. 74-75. <http://eprints.ucm.es/42077/1/Objecci\%C3\%B3n-Palomino.pdf>, consultada el 9 de abril de 2018.

47 Cfr., <http://www.poderjudicial.es/search/contenidos.action?action=co ntentpdf\&databasematch $=$ TS \&reference $=4599992 \&$ links $=\&$ optimize $=2009$ 0611 \&publicinterface $=$ true $>$, consultada el 9 de abril de 2018 . 
10. Considérant qu'en ne permettant pas aux officiers de l'état civil de se prévaloir de leur désaccord avec les dispositions de la loi du 17 mai 2013 pour se soustraire à l'accomplissement des attributions qui leur sont confiées par la loi pour la célébration du mariage, le législateur a entendu assurer l'application de la loi relative au mariage et garantir ainsi le bon fonctionnement et la neutralité du service public de l'état civil ; qu'eu égard aux fonctions de l'officier de l'état civil dans la célébration du mariage, il n'a pas porté atteinte à la liberté de conscience; ${ }^{48}$

En caso contrario, en Canadá la Civil Marriage Act S.C. 2005, c. 33, que reconoce el matrimonio entre personas del mismo sexo, sí establece un apartado específico en el que se otorga el derecho a la objeción de conciencia a toda persona que deba intervenir en los mismos, al respecto en sus artículos 3. Y 3.1 establece:

Religious officials

3 It is recognized that officials of religious groups are free to refuse to perform marriages that are not in accordance with their religious beliefs.

Freedom of conscience and religion and expression of beliefs

3.1 For greater certainty, no person or organization shall be deprived of any benefit, or be subject to any obligation or sanction, under any law of the Parliament of Canada solely by reason of their exercise, in respect of marriage between persons of the same sex, of the freedom of conscience and religion guaranteed under the Canadian Charter of Rights and Freedoms or the expression of their beliefs in respect of marriage as the union of a man and woman to the exclusion of all others based on that guaranteed freedom. ${ }^{49}$

48 Cfr., <http://www.conseil-constitutionnel.fr/conseil-constitutionnel/francais/les-decisions/acces-par-date/decisions-depuis-1959/2013/2013-353-qpc/ decision-n-2013-353-qpc-du-18-octobre-2013.138338.html>, consultada el 12 de abril de 2008.

49 Cfr., <http://laws-lois.justice.gc.ca/eng/acts/c-31.5/page-1.html>, consultada el 12 de abril de 2008. 
En Dinamarca, con la introducción de la ley de parejas de hecho se estipularon cláusulas de conciencia para las personas que pueden intervenir en los matrimonios entre personas del mismo sexo, excluyendo a las parejas del mismo sexo de la libertad de elección entre el matrimonio religioso y civil, precisamente para que los pastores de la iglesia luterana oficial, que tienen una condición equivalente a la de funcionarios públicos, no se vean constreñidos a intervenir en esos matrimonios. ${ }^{50}$

Finalmente, en los Estados Unidos de Norteamérica, la Corte del Distrito de Columbia en el caso Haring, ${ }^{51}$ en el que un oficial del Internal Revenue Service, se negaba a calificar las peticiones de excepción de impuestos de organizaciones que practicaban abortos, pasándolas a otros compañeros. El IRS negó su oportunidad de ascender de puesto aduciendo de podía "seducir" a otros compañeros. El Tribunal otorgó la razón al demandante y estableció que la oficina en la que laboraba, como cualquier empresa, debía acomodarse a los disentimientos de sus empleados basados en razones de conciencia y que las funciones sobre las que se objetó, cuando no son dañinas para el estado, pueden llevarlas a cabo otros funcionarios, y han de ser protegidas. ${ }^{52}$

\section{Vi. A manera de CONCLUSIONES}

La objeción de conciencia como "una concreción de la libertad de conciencia que dentro de los justos límites, lleva a un individuo a incumplir una determinada disposición legal que le obliga -bajo sanción o privación de un beneficio- a obrar en contra de su con-

50 Rafael Navarro Valls, "La objeción de conciencia a los matrimonios...", op . cit. p. 283-284.

51 Federal Supplement, District of Columbia, vol. 471, 1979, p. 1172

52 Rafael Navarro Valls, "La objeción de conciencia a los matrimonios...", op. cit. p. 283. 
ciencia o le impide obrar conforme a ella", ${ }^{53}$ es un fenómeno jurídico actual sumamente complejo que debe ser analizado en cada caso pues sus implicaciones, de llegar a existir una declaratoria general, son sumamente trascendentes pudiendo llegar a influir en la estructura misma del estado.

En el caso de México la objeción de conciencia se encuentra jurídicamente prohibida, sin embargo derivado de los avances en materia de derechos humanos y atendiendo a interpretaciones más amplias de los tratados internacionales en materia de derechos humanos puede concluirse que la misma puede ser invocada por las personas ante ciertas obligaciones legales.

Respecto de los Jueces del Registro Civil, legalmente se encuentran obligados a celebrar los matrimonios entre personas del mismo, aun cuando dicho actuar atente contra sus convicciones personales, toda vez que al actuar como funcionarios del estado, deben prestar el servicio público que les fue encomendado en aras de salvaguardar el estado de derecho y respetar los derechos de los gobernados quienes solicitan un servicio público.

En ese mismo sentido, los tribunales de diversos países con una tradición más añeja en el tema de la objeción de conciencia y con una jurisprudencia más rica, la cual cabe mencionar en veces puede llegar a ser contradictoria, se han pronunciado respecto que la imposibilidad de que los funcionarios públicos encargados de celebrar matrimonios entre personas del mismo sexo puedan acudir a una cláusula de conciencia.

Si bien es cierto, en otras naciones se ha reconocido ese derecho y se plasmado en la ley, cabe considerar que obedece a motivos distintos, toda vez que en las que se refirieron anteriormente, Canadá y Dinamarca, los ministros de culto de las iglesias pueden celebrar matrimonios con validez ante el estado, y ante la invocación de una cláusula de conciencia por parte de estos, hay funcionarios guber-

53 Dora María Sierra Madero, op. cit, p. 17. 
namentales encargados de llevar a cabo esta tarea, situación que en México no acontece pues los únicos encargados de celebrar matrimonios con reconocimiento estatal son los funcionarios designados para ese efecto, por lo que no actúan a nombre propio o de alguna confesión religiosa, sino en representación del Estado.

En este punto, y en el caso de que llegara a permitirse la objeción de conciencia a los oficiales del registro civil, mediante la incorporación de alguna disposición legal, lo cual no sería sorpresivo en el caso de la Ciudad de México atendiendo al carácter progresista en materia de derechos que ha tenido en los últimos años y a que ya ha habido una intención de incorporarla, habría que tener un especial cuidado institucional para no dejar en estado de incertidumbre a las parejas del mismo sexo que decidan contraer matrimonio, pues podría convertirse en una medida para desincentivar a este tipo de uniones.

En esa tónica, si bien no se desconoce que todas las personas tienen derecho a la libertad de conciencia y a actuar conforme a sus convicciones, incluidos los servidores públicos, éstos últimos cuando actúan en esa calidad no lo hacen a título personal sino en representación del estado para la consecución de los fines del mismo.

Por lo que, la objeción de conciencia de estos funcionarios debe analizarse con mucha prudencia para determinar las posibles implicaciones que pudiera tener directamente, así como para evitar que la misma pudiera ser hecha valer todos los funcionarios públicos que, en cualquier tipo de actividad que realicen y consideren contraria a su conciencia pudieran objetar, lo que llevaría al extremo de supeditar las funciones del estado a las convicciones de sus funcionarios, situación que no es jurídicamente admisible.

Así mismo, de llevarse a cabo la modificación legislativa antes referida ese derecho no podría ser ilimitado, sino que debería restringirse para no afectar derechos de las parejas del mismo sexo que pretendan unirse en matrimonio, como en el caso de que, de no haber otro juez disponible éste no podría objetar, como sucede en 
las legislaciones que permiten a los médicos objetar en conciencia con sus justas limitaciones.

Sin embargo este proceder traería como consecuencia un incremento del aparato burocrático estatal, que podría considerarse injustificado, cuya pertinencia habría que analizar con detenimiento, para establecer si debería existir un juez sustituto o suplente en su caso, para no menoscabar el derecho de los contrayentes de acudir ante el juez de su elección, como podría serlo el más cercano a su domicilio, empero esto podría llevar al extremo de que existan jueces sólo para llevar a cabo matrimonios entre personas del mismo sexo y otro sólo para matrimonios tradicionales, lo cual podría considerarse como una práctica discriminatoria.

Es por todo lo expuesto, que aun cuando los oficiales del registro civil tienen derecho a actuar conforme a su conciencia, eso debe interpretarse sólo en su ámbito personal, más no cuando llevan a cabo funciones públicas en representación del estado, atendiendo al principio constitucional de que el Estado Mexicano será laico, lo que no implica intromisión alguna en su fuero interno pues como se dijo su actuar al celebrar matrimonios es en representación del estado atendiendo al cargo público que ostentan.

\section{Vil. Fuentes de consulta}

\section{BiBLIOGRÁFICAS}

Arlettaz Fernando, Matrimonio homosexual y secularización, México, UNAM, 2015.

Gañamares Arribas, Santiago, "Las objeciones de conciencia", en Jusdado Ruiz-Capillas Miguel Ángel (dir.), Derecho Eclesiástico del Estado, Madrid, Colex, 2012.

Navarro-Valls, Rafael, "Las objeciones de conciencia", en Ferrer Ortiz, Javier (Coord.), Derecho Eclesiástico del Estado Español, Pamplona, Eunsa, 2004. 
Soto Obregón, Martha Elena, Objeción de conciencia: ¿Testigos de Fehová vs. simbolos patrios., México, Plaza y Valdés, 2003.

Sierra Madero, Dora María, La objeción de conciencia en México. Bases para un adecuado marco jurídico, México, UNAM, 2012.

Suprema Corte de Justicia de la Nación, Decisiones relevantes de la Suprema Corte de Justicia de la Nación, núm. 65, El matrimonio entre personas del mismo sexo en la legislación del Distrito Federal y sus efectos jurídicos, México, México, Suprema Corte de Justicia de la Nación, UNAM, Instituto de Investigaciones Jurídicas, 2013.

Trejo Osorno, Luis Alberto, La objeción de conciencia en México, México, Porrúa, 2010.

\section{Hemerográficas}

Allier Campuzano, Jaime, "Improcedencia de la objeción de conciencia planteada por un juzgador", en Revista del Instituto de la Fudicatura Federal, México, México, núm. 33, 2012, pp.15-18.

Borillo, Daniel, "Pluralisme conjugal ou hiérarchie des sexualités? La reconnaissance juridique des couples homosexuels dans l'Union Européenne", en McGill Law Journal, Canada, Montreal, núm. 46, 2001, p.877.

Martínez-Torron, Javier, "Las objeciones de conciencia y los intereses generales del ordenamiento", en Revista de la Facultad de Derecho de la Universidad Complutense, España, Madrid, No. 79, 1992, p.200.

Navarro-Valls, Rafael, "La objeción de conciencia a los matrimonios entre personas del mismo sexo", en Persona y Derecho, España, Pamplona, número 53, 2005, pp. 259 -260.

Palomino, Rafael, "Objeción de conciencia de los notarios españoles con motivo de la nueva ley de jurisdicción voluntaria", en Revista furidica Digital UANDES, España, 2017, pp. 74-75. <http://eprints.ucm. es/42077/1/Objecci\%G3\%B3n-Palomino.pdf>, consultada el 9 de abril de 2018 . 
Valadez, Diego, "La no aplicación de las normas y el Estado de Derecho", Boletin Mexicano de Derecho Comparado, México, México, nueva serie, año XXXV, núm. 103, enero-abril de 2002, pp.281-286.

\section{JURISPRUDENCIALES}

la./J. 43/2015 (10a.), Gaceta del Semanario Judicial de la Federación, Décima Época, Libro 19, Junio de 2015, Tomo I, Pag. 536.

Amparo indirecto 176/2018-I, del índice del Juez Primero de Distrito en el Estado de Guanajuato.

Amparo en revisión 84/2017 del Tercer Tribunal Colegiado en Materias Administrativa y Civil del Vigésimo Segundo Circuito.

Amparo en revisión 174/2016 del Tercer Tribunal Colegiado en Materias Civil y de Trabajo del Quinto Circuito.

Federal Supplement, District of Columbia, vol. 471, 1979, p. 1172

\section{SITIOS DE INTERNET}

<http://hj.tribunalconstitucional.es/es/Resolucion/Show/892>, consultada el 15 de abril de 2018.

<http://bovmsilap.scjn.pjf.gob.mx/Buscador/Paginas/wfArticuladoF ast. aspx?q=BHGGbWrG7ukiUiW/WEuu/p8LleK/aAiRW $/$ NIyDBMGeD26fQH4D1AS76ba9QpHZqdlVXcNDeh0Y9LdZ0 j9Mrorw==>, consultada el 12 de abril de 2018.

<http://www.un.org/es/universal-declaration-human-rights/>, consultada el 17 de abril de 2018.

<http://bovmsilap.scjn.pjf.gob.mx/Buscador/Paginas/wfArticuladoF ast.aspx?q=zmlkJ/89AXJJKRY4OR4AdHR5D7ybEDVwR9piyud TPqf7Otvf1sBBSN7TV9QyUgNtOf/RTQxb1HYEV5YnPs3rZ $\mathrm{g}==>$, consultada el 18 de abril de 2018 .

<https://www.oas.org/dil/esp/tratados_b-32_convencion_americana_ sobre_derechos_humanos.htm>, consultada el 18 de abril de 2018. 
<http://www.aldf.gob.mx/archivo-c034f9df29cc68890266a50380f5 c8ab.pdf>, consultada el 18 de abril de 2018.

$<$ http://congresoweb.congresojal.gob.mx/BibliotecaVirtual/busquedasl eyes/Listado.cfm\#Leyes>, consultada el 18 de abril de 2018.

<http:/ / www.senado.gob.mx/index.php?ver=sp\&mn=2\&sm $=1 \& i d=2231>$, consultada del 24 de abril de 2018 .

<http://hudoc.echr.coe.int/webservices/content/pdf/001-115881?TID $=$ pxlmztpkug $>$, consultada el 10 de abril de 2018.

<https://www.secularism.org.uk/news/2014/09/secularists-express -concern-over-council-decision-to-accommodate-religious-refusal -to-conduct-same-sex-weddings1>, consultada el 25 de abril de 2018.

<http://www.poderjudicial.es/search/contenidos.action?action=content pdf\&databasematch $=$ TS\&reference $=4599992 \&$ links $=\&$ optimize $=20090611$ \&publicinterface $=$ true $>$, consultada el 9 de abril de 2018.

<http://www.conseil-constitutionnel.fr/conseil-constitutionnel/francais /les-decisions/acces-par-date/decisions-depuis-1959/2013/2013353-qpc/decision-n-2013-353-qpc-du-18-octobre-2013.138338. html>, consultada el 12 de abril de 2008.

<http://laws-lois.justice.gc.ca/eng/acts/c-31.5/page-1.html>, consultada el 12 de abril de 2008. 